\title{
Investigation of the Moderating Role of Perceived Vulnerability to Infectious Diseases Regarding the Relationship between Disgust and Fear of Contamination
}

\author{
Mona Moradi Motlagh1, Mohammad Reza Nainian,; (D), Ladan Fata ${ }^{3}$, Mohammad \\ Gholami Fesharaki ${ }^{4}$, Gholamhossein Ghaedi ${ }^{5}$ \\ I PhD Student in Clinical Psychology, School of Humanities, Shahed University, Tehran, Iran \\ 2 Assistant Professor, Department of Clinical Psychology, School of Humanities, Shahed University, Tehran, Iran \\ 3 Assistant Professor, Department of Medical Education, School of Medicine, Iran University, Tehran, Iran \\ ${ }^{4}$ Assistant Professor, Department of Biostatistics, School of Medical Sciences, Tarbiat Modarres University, Tehran, Iran \\ ${ }^{5}$ Associate Professor, Department of Psychiatry, School of Medicine, Shahed University, Tehran, Iran \\ * Corresponding Author: Mohammad Reza Nainian, Department of Clinical Psychology, School of Humanities, Shahed \\ University, Tehran, Iran. Email: mrnainian@yahoo.com
}

Received: 10.01.2019

Accepted: 13.04.2019

How to Cite this Article: Moradi Motlagh M, Nainian MR, Fata L, Gholami Fesharaki M, Ghaedi Gh. Investigation of the Moderating Role of Perceived Vulnerability to Infectious Diseases Regarding the Relationship between Disgust and Fear of Contamination. Avicenna J Clin Med. 2019; 26(1): 34-43. DOI: 10.29252/ajcm.26.1.34

\section{Abstract}

Background and Objective: Several studies revealed that disgust as an emotional response underlies the contamination fears in Contamination Obsessive Compulsive Disorder (OCD). Other studies supported the role of cognitions related to contagion and disease in contamination OCD. The present study aimed to integrate these two lines of evidence. To this end, regarding the concept of the behavioral immune system, it was investigated whether perceived vulnerability to infectious disease, as a cognitive component of the behavioral immune system, can moderate the relation between disgust, as the emotional component of this system, and symptoms of contamination OCD.

Materials and Methods: This cross-sectional study was conducted on 350 university students in Tehran University through cluster random sampling. The participants were asked to complete the Persian version of the disgust scale, perceived vulnerability to disease questionnaire, and Vancouver contamination subscale. The data were analyzed utilizing hierarchical regression analysis and post hoc tests.

Results: The results revealed that perceived vulnerability to infectious disease moderated the relationship between the feeling of disgust and fear of contamination. According to the results, perceived infectability subscale which measures perceived weakness of one's immune system with more accuracy, can also exacerbate the relationship between the feeling of disgust and fear of contamination.

Conclusion: The results of this study facilitate the understanding of the effect of disgust on fear of contamination, especially the role of cognitions about contagion and disease in potentiating the relation between disgust and contamination OCD. Moreover the obtained results generally provide evidence for the disease-avoidance theory in disgust and support the possible hyperactivity of the behavioral immune system in contamination OCD.

Keywords: Behavioral Immune System, Contamination Fear, Disgust, Obsessive -Compulsive Disorder, Perceived Vulnerability 


\section{بررسى نقش تعديلكننده آسيبذيذيرى ادراكشده نسبت به بيمارى مسرى در رابطه بين جندش و ترس از آلودىى}

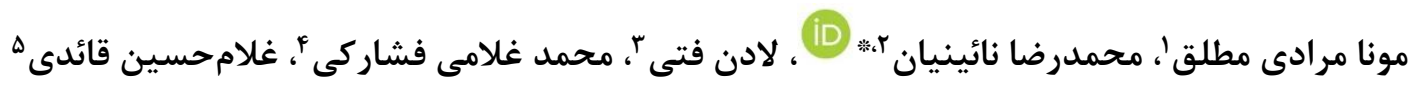
' انشجوى دكترى روانشناسى بالينى، دانشكده علوم انسانى، دانشگاه شاهد، تهران، ايران

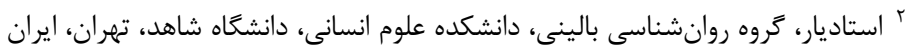

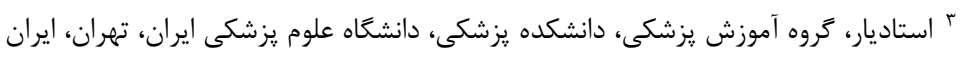

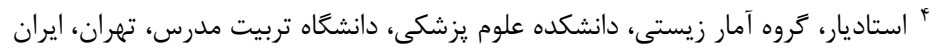

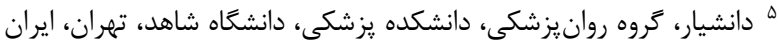
* نويسنده مسئول: محمدرضا نائينيان، استاديار، كروه روانشناسى بالينى، دانشكده علوم انسانى، دانشكاه شاهد، تهران، ايران. ايميل: mrnainian@yahoo.com

\begin{tabular}{|c|c|}
\hline 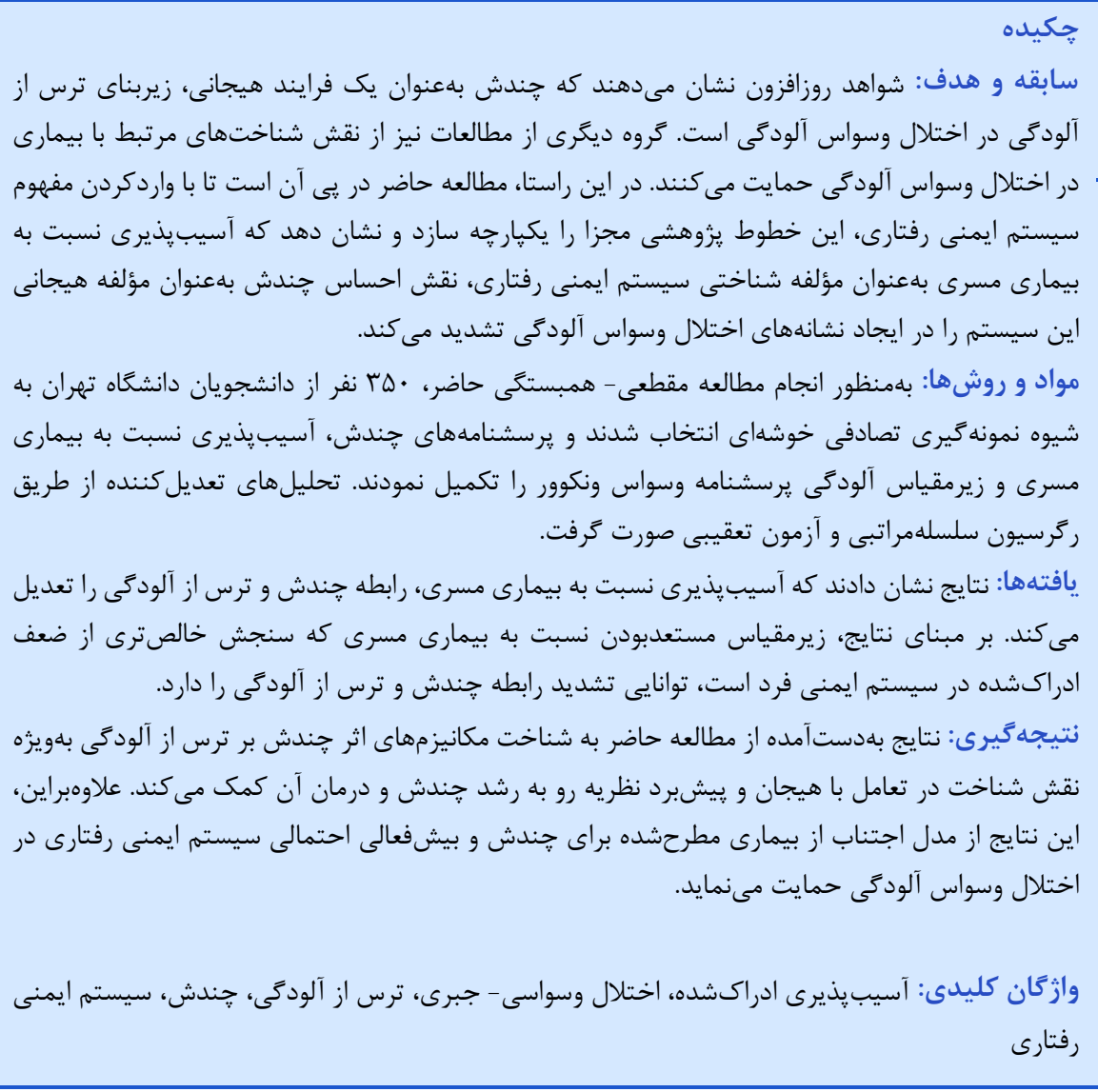 & 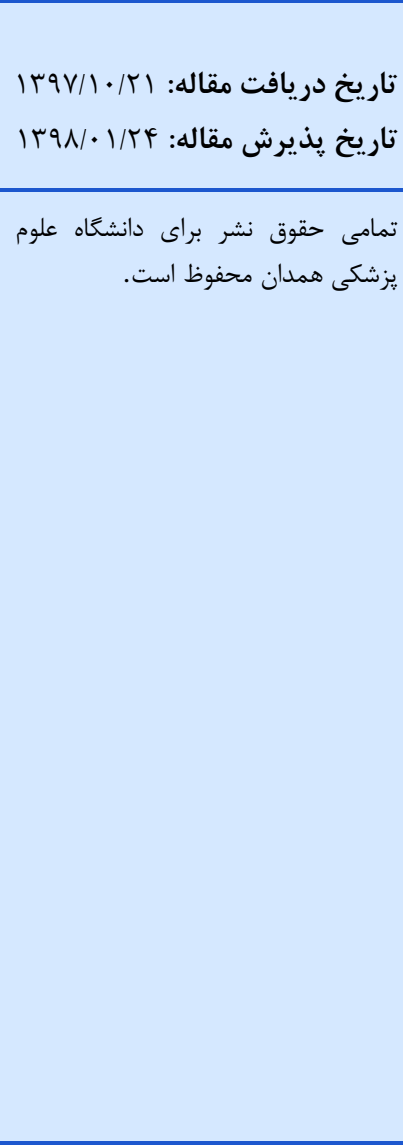 \\
\hline
\end{tabular}

طول عمر افراد بين ا تا و/ا درصد است [ب]. اترجه اختلال وسواس بهعنوان يك طبقه تشخيصى واحد در نظر گرفته مى أشود

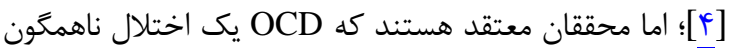

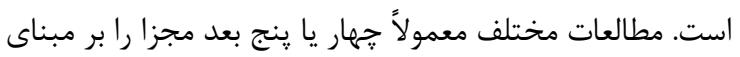

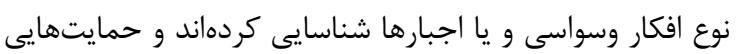

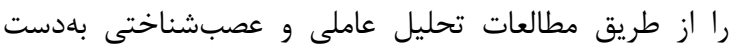

OCD: Obsessive-) اختلال وسواسى - جبرى (Compulsive Disorder

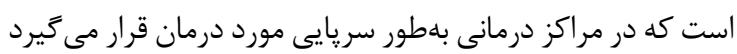

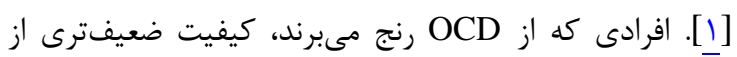

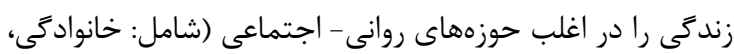

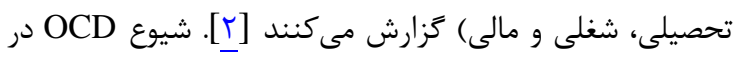


آشكار جندش است؛ بهعنوان مثال دستمالهاى كثيف و لنَن

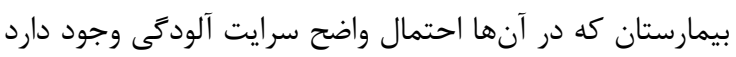

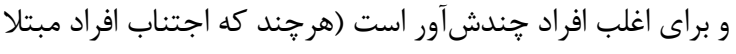
به وسواس از جنين محركهايى شديدتر است) و و گاهى

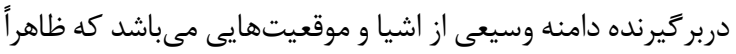

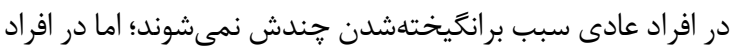

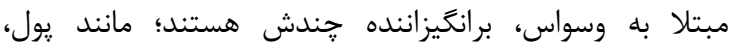
تلفنهاى عمومى، دستخيرههاى در، دكمههاى آسانسور و نردههاى

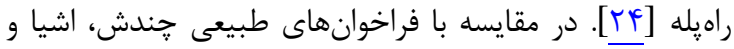

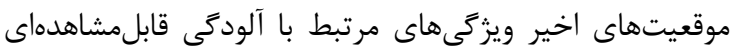
ندارند و همين امر درك اجتناب افراد مبتلا به وسواس از ائ اين نوع

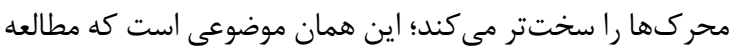

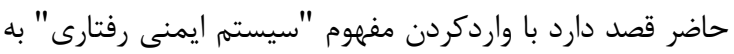

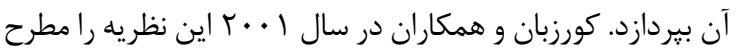

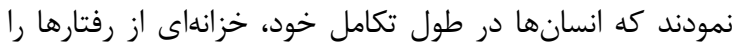

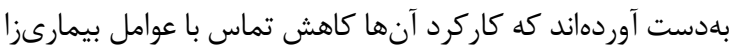

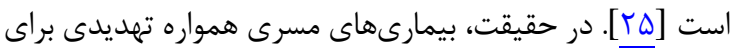

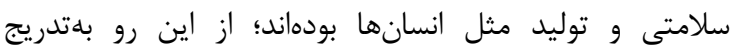

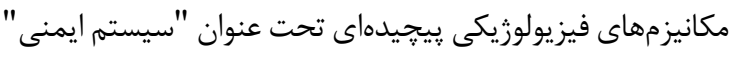

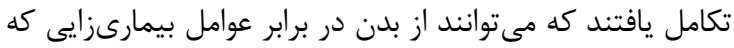

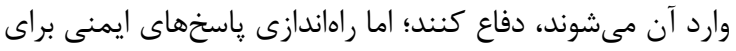

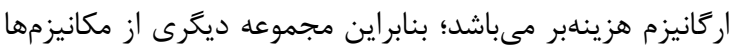

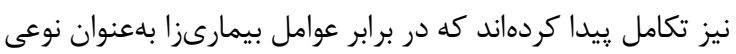

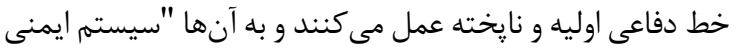

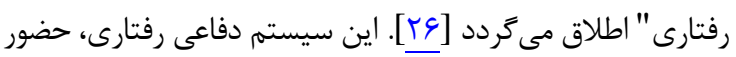

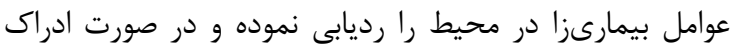

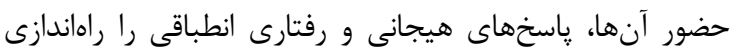

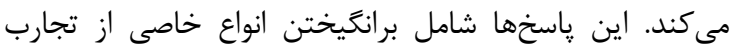

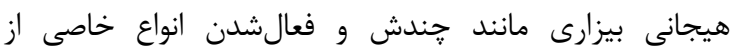

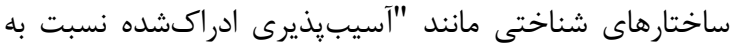
بيمارى" (Perceived Vulnerability to Disease) در حافنارئنس كارى است كه در نهايت اجتناب رفتارى از عوامل بيمارىزا را

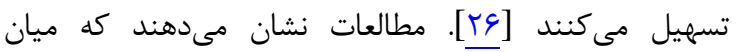
مؤلفههاى سيستم ايمنى رفتارى و سيستم ايمنى بدن رابن رابطه

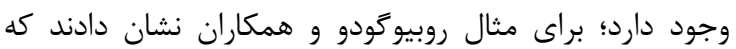

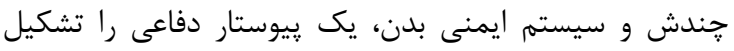

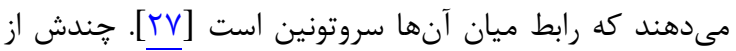

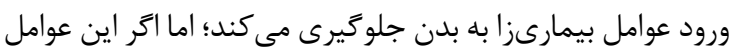
وارد بدن بشوند، نوبت سيسته ايمنى است كه با آنها مقابله كند.

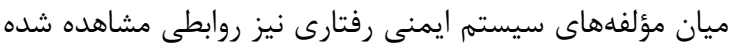

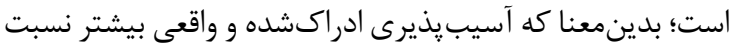

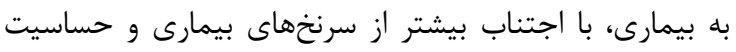

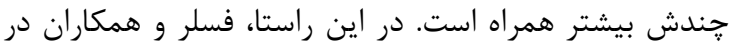

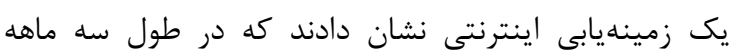

آوردهاند [ـ- [- ]. با وجود برخى از تغييريذيرىها در شيوع ابعاد

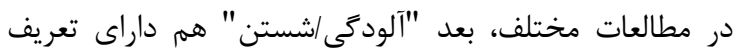

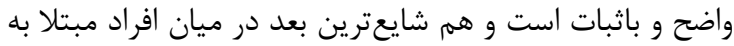

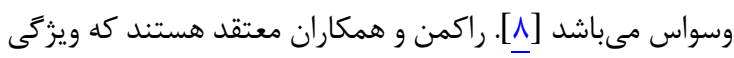

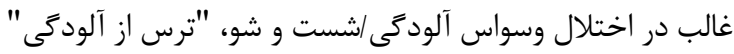
(Fear of Contamination) احساس شديد و ثابت ترس از آلودهشدن، كثيفشدن، بيمارشدن

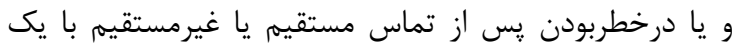
شى/شخص/مكان كه بهصورت آلوده، كثيف، ناياك، عفونى و يا ديا

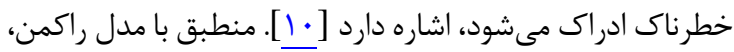

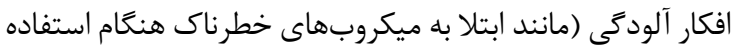

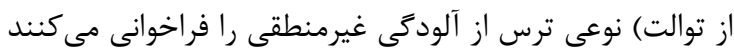

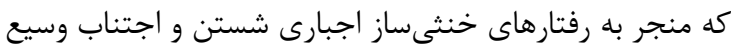

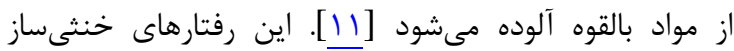

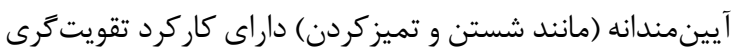

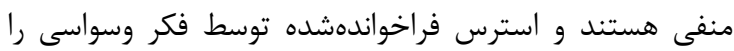

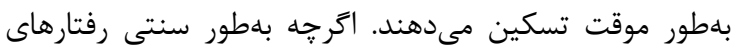

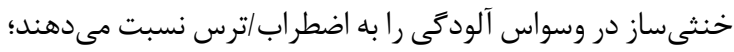

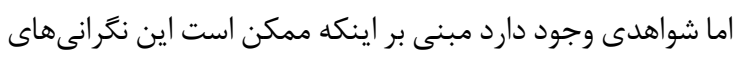

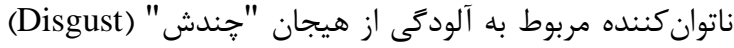

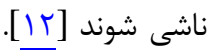

جندش يكى از هيجانات بنيادين مطرحشده از سوى داروين

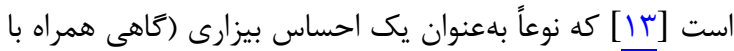

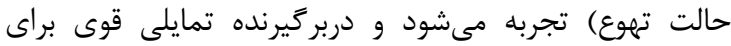

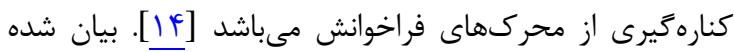
است كه جندش سبب برانگيختهشدن اجتناب از خوردن و و تماس

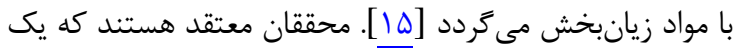

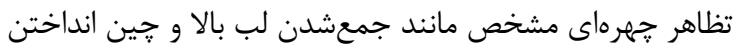

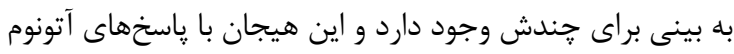

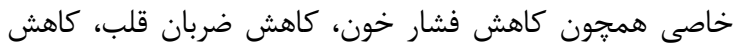

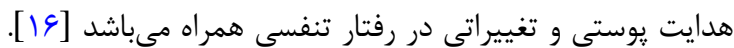
يزوهشهاى بسيارى جندش را در علتشناسى و تداوم اختلال

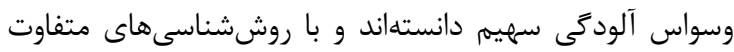

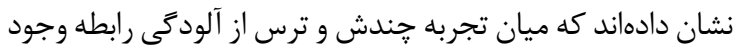

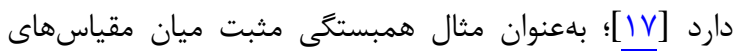

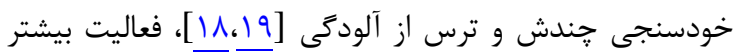

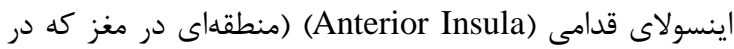
يردازش جندش دخيل است) در طول مواجهه با محركهاى

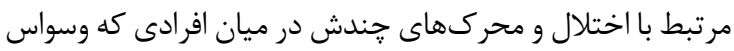

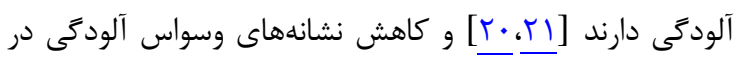

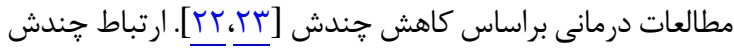

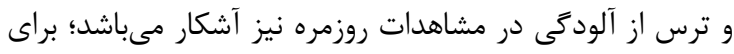

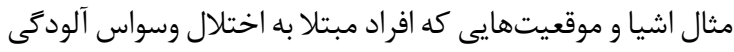

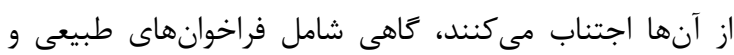


روانى آشكار. دانشجوى مهمان بودن و حجم بالاى دادههاى

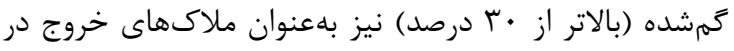

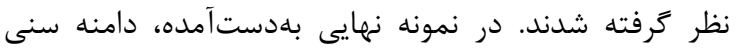

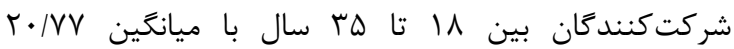

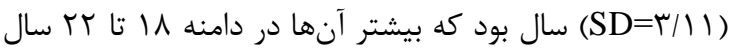

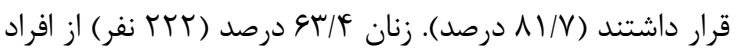
نمونه را تشكيل دادند. در توضيح علت انتخاب نمونه حاضر بايد

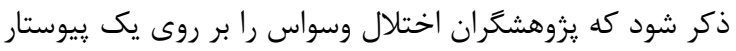

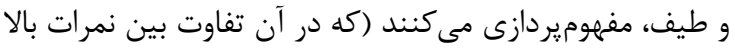

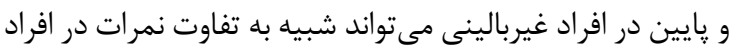

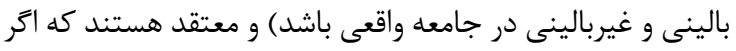
روابط مفروض در اين طيف وجود داشته باشد، به احتمال زياد

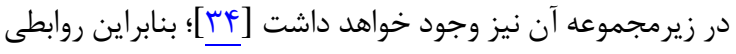
كه براى نخستين بار مورد مطالعه قرار مى گيرند، ابتدا در نمونه

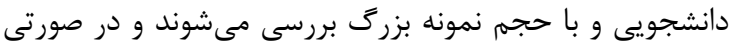

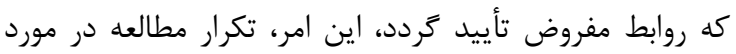

نمونه بالينى را موجه مىسازد [IV]

\section{ابزارها}

الف. زيرمقياس آلودكى يرسشنامه وسواسى- جبرى ونكوور

VOCI-C: Vancouver Obsessional Compulsive ) (Inventory- Contamination Subscale در حقيقت فرم تجديدنظرشده يرسشنامه وسواسى - جبرى مادزلى

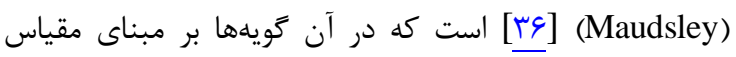
ليكرت ينج گزينهاى درجابندى مىشوند. اين يرسشنامه داراى

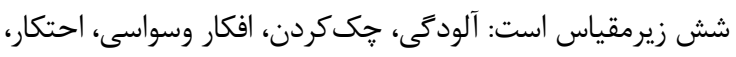

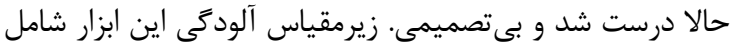

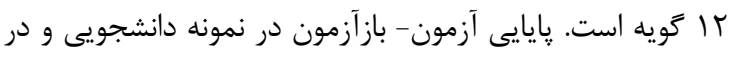

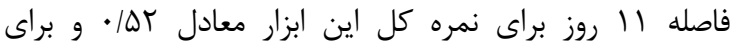

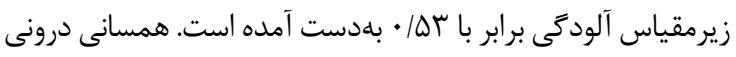

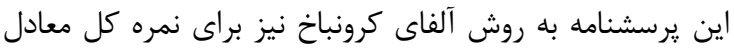

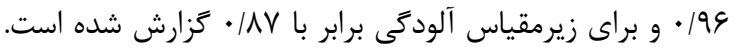

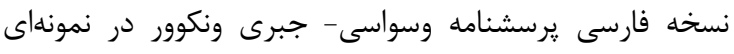

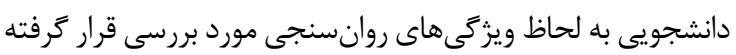

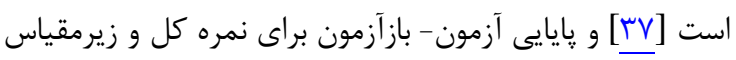

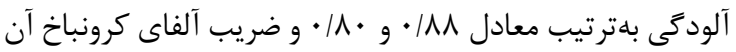

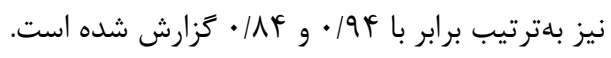

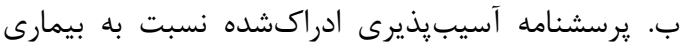

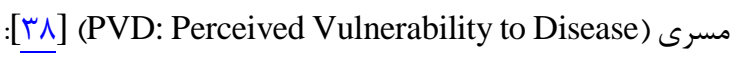
اين يرسشنامه داراى لها تويه خودسنجى است كه هركدام بر

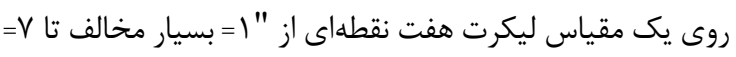

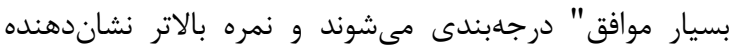

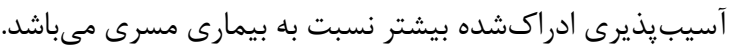

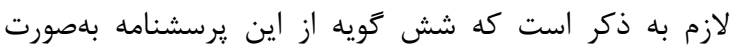

نخست باردارى كه به دليل فرونشانى سيستم ايمنى بدن مادر،

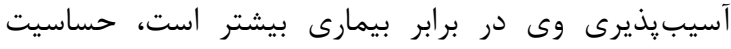

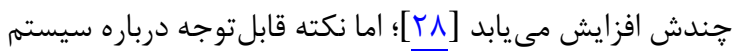

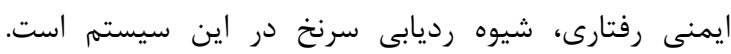

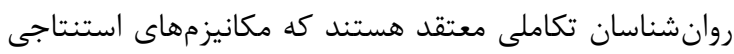

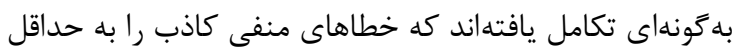

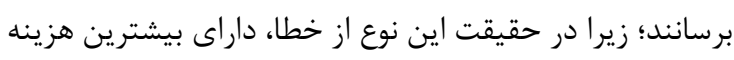

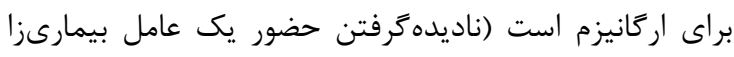

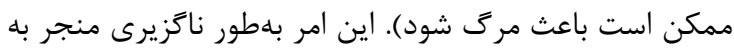

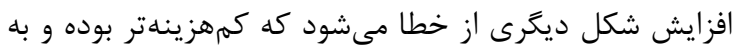

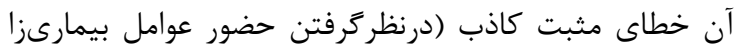

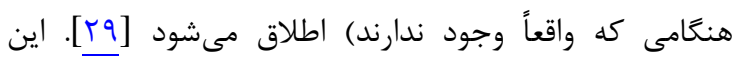

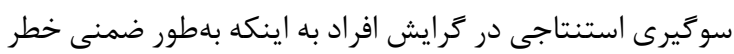

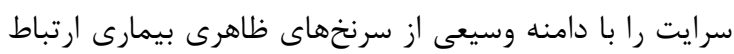

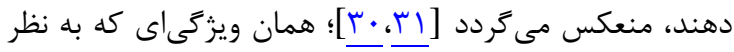

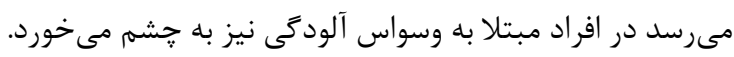

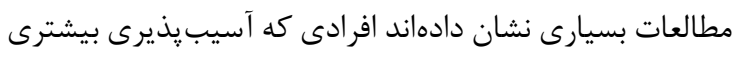

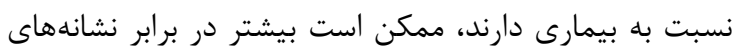

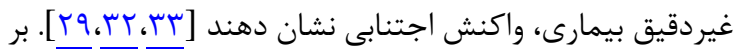

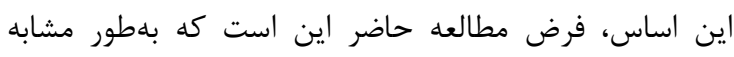

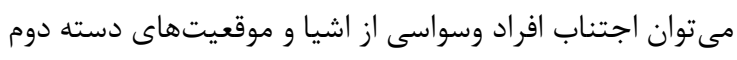

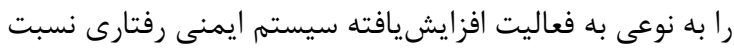

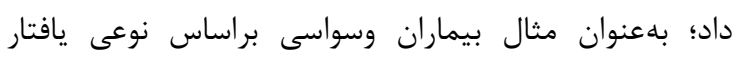

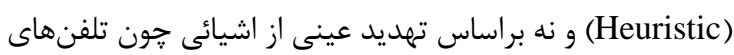

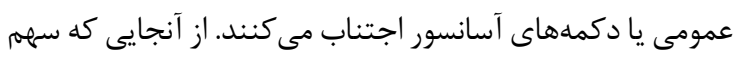

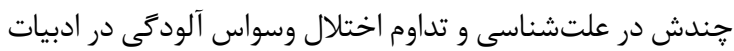
يزوهش مستند شده است، مىتوان اين فرضيه را مطرح كرد كه

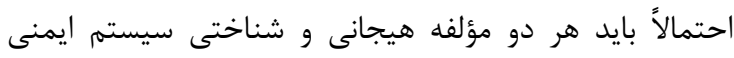

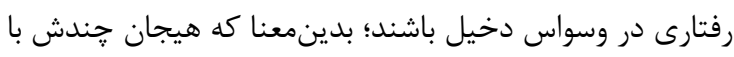

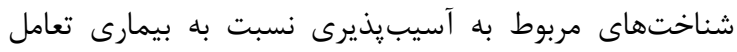

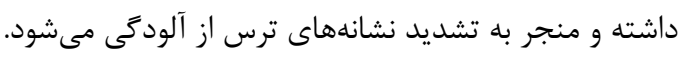

\section{مواد و روشها}

جامعه شركت كنندگان در مطالعه مقطعى- همبستخى حاضر

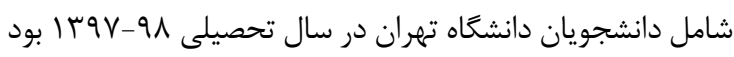

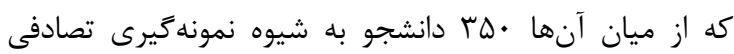

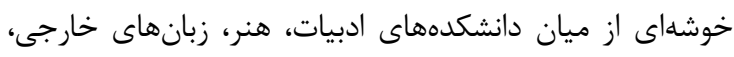

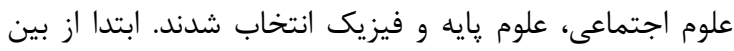

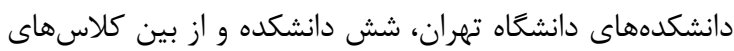

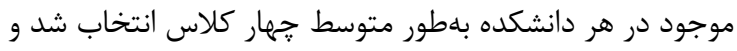

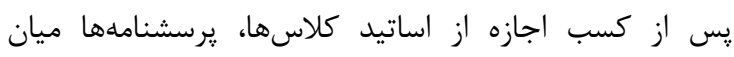
دانشجويان توزيع گرديد. ملاكهاى ورود به مطالعه حاضر إن عبارت

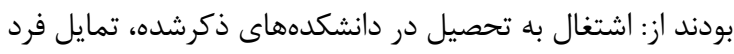

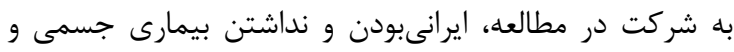


و همكاران به بررسى ويزگى هاى روانسنجى مقياس جندش

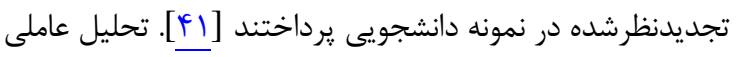

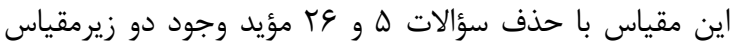

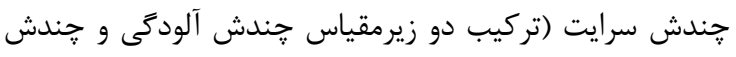
بنيادين) و جندش يادآور حيوانى بود. آلفاى كرونباخ كل اين

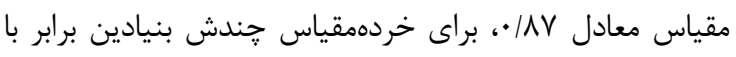

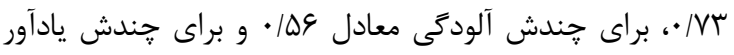

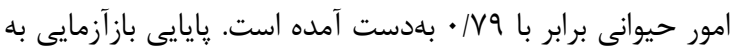

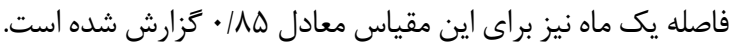

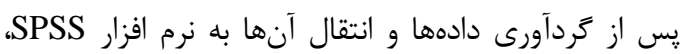

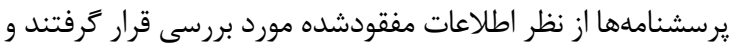

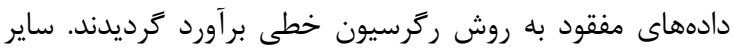

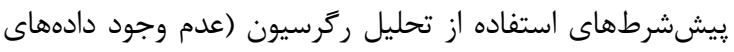

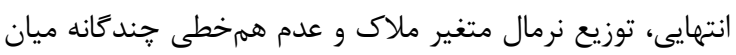

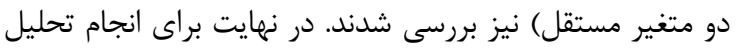

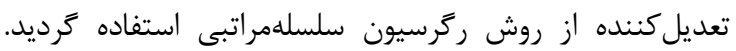
حداقل حجم نمونه لازم براى انجام تحليلهاى ركرئ ركرسيون

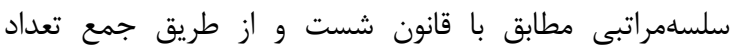

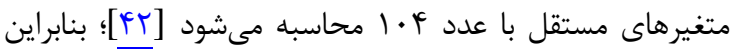
حداقل نمونه لازم براى مطالعه حاضر برابر با و • ا نفر بود.

\section{مسائل اخلاقى}

بايد خاطرنشان ساخت كه در مورد نوع مطالعه و فعاليتى كه

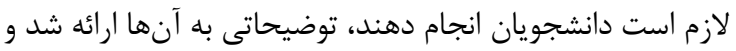

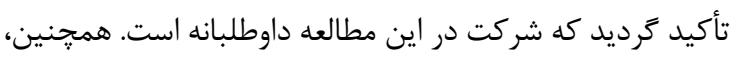

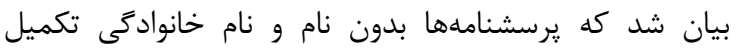

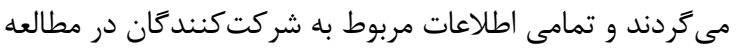
بلهورت محرمانه نكَهدارى خواهند شد.

\section{1. بافته}

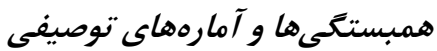

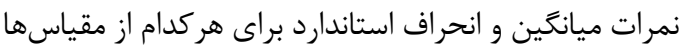

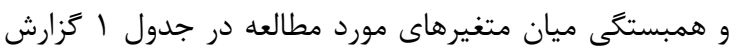

معكوس نمرهزذارى مىشوند. يرسشنامه آسيب يذيرى ادراكشده نسبت به بيمارى مسرى شامل دو زيرمقياس است: مستعدبودن براى ابتلا به بيمارى مسرى از نظر ذهنى (براى مثال "من بهلهوري

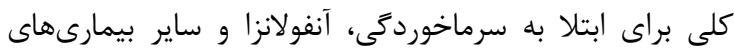

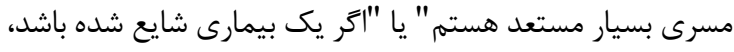

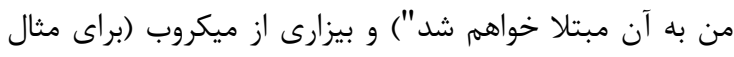

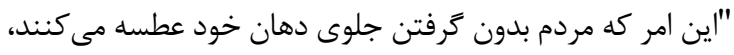

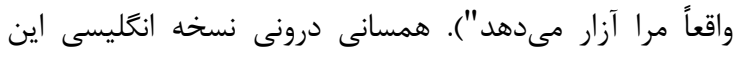

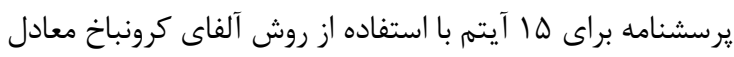

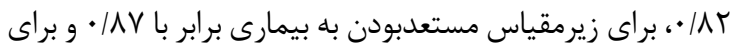

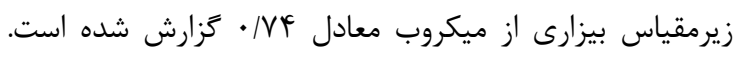

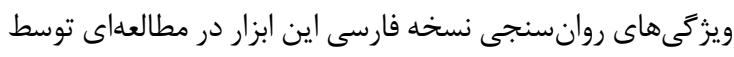

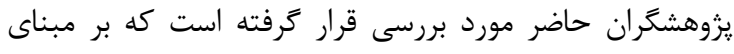

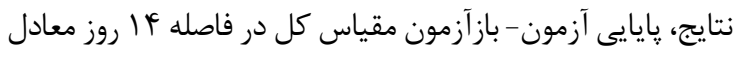

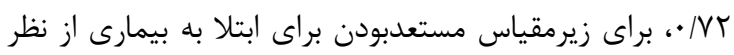

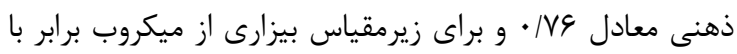

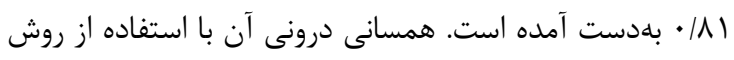

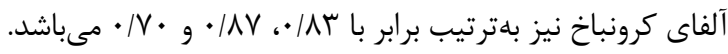

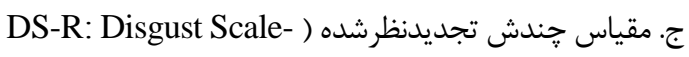
(Revised

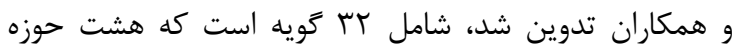

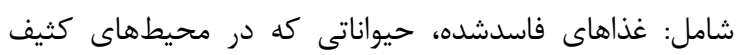

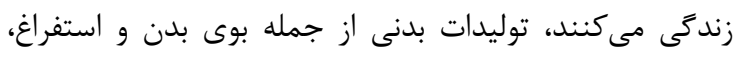
جراحات يوستى، مرى و اجساد، رفتارهايى كه از نظر جامعه

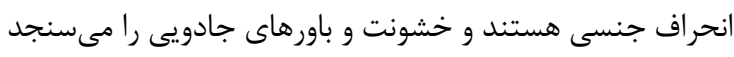

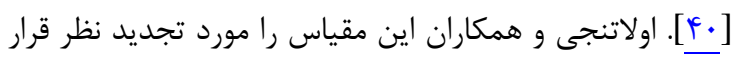

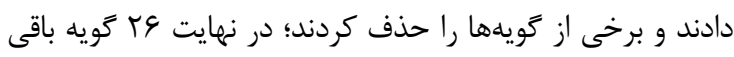

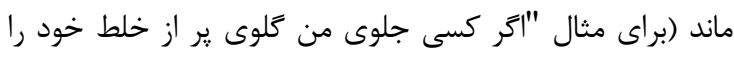

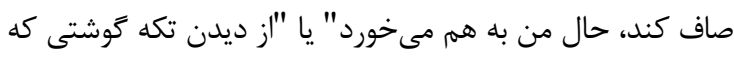

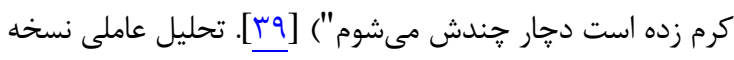

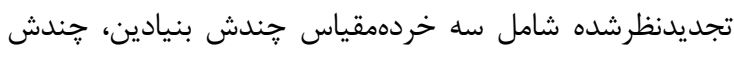

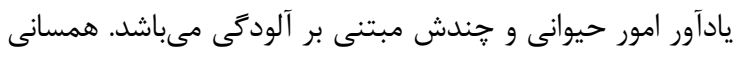

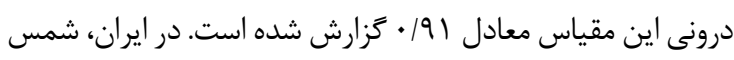

\begin{tabular}{|c|c|c|c|c|c|}
\hline \multirow[t]{5}{*}{ (ब) } & $(\boldsymbol{F})$ & $(\boldsymbol{r})$ & $(Y)$ & (1) & مقياسها \\
\hline & & & & 1 & (1) مقياس جندش \\
\hline & & & 1 & $* 109$ & (r) زيرمقياس وسواس آلودَى ونكوور \\
\hline & & 1 & 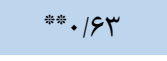 & 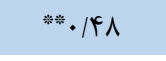 & (T) يرسشنامه آسيبيذيرى ادراكشده نسبت به بيمارى \\
\hline & 1 & 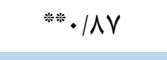 & $\stackrel{* *}{* *} \cdot / \%$ & $* * / T \omega$ & (F) زيرمقياس مستعدبودن براى ابتلا به بيمارى \\
\hline 1 & ${ }^{* *} \cdot / r V$ & $\stackrel{* * *}{*} \cdot / V V$ & 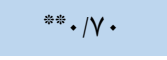 & ${ }^{* * * *} \cdot 109$ & (ه) زيرمقياس بيزارى از ميكروب \\
\hline$(1 / 1 r) r / \Delta V$ & $(1 / r 1) r / 99$ & $(1 / \cdot r) r / g r$ & $(\cdot \mid \lambda \cdot)|/ 4|$ & $(\cdot / 9 T) T / 19$ & ميانكين كل (انحراف معيار) \\
\hline$(1 / 1 F) r / T q$ & $(1 / I V) r / \Delta Q$ & $(\cdot / 9 V) r / F F$ & $\left(\cdot / V F^{F}\right) \backslash / T \Lambda$ & $(\cdot / 9 T) 1 / 9 Y$ & ميانغين مردان (انحراف معيار) \\
\hline$(1 / 1 \cdot) r / N F$ & $(1 / \Gamma \Lambda)$ r/VG & $(1 / \cdot r) r / V \Delta$ & $(\cdot \mid \Lambda \Gamma) \mid / F \Lambda$ & $(\cdot \mid \Delta \Lambda) T / \mu r$ & ميانگين زنان (انحراف معيار) \\
\hline
\end{tabular}

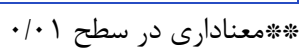


آسيبذيذيرى ادراكشده به بيمارى مسرى (نمرات يك انحراف

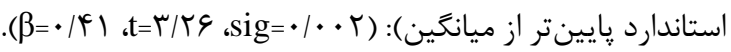

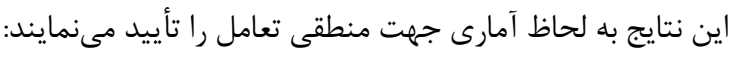

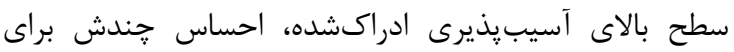
بيشبينى ترس از آلودىى را تشديد مى كند.

نقش تعديل كننده زيرمقياس مستعدبودن براى ابتلا به

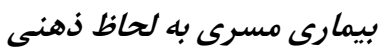
از آنجايى كه از ميان زيرمقياسهاى آسيبيذيرى در برابري

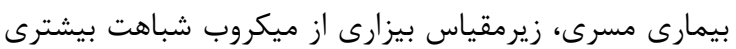

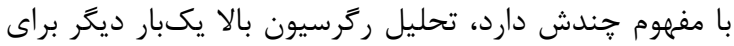

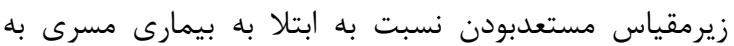

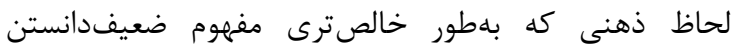

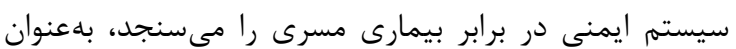

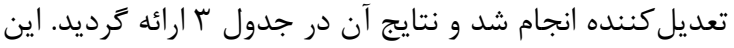

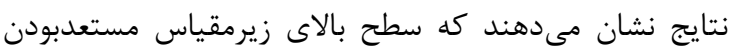

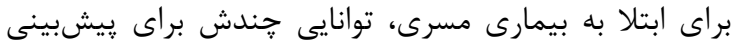

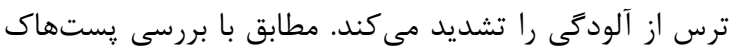

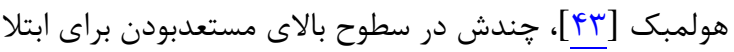
به بيمارى مسرى از نظر ذهنى (نمرات يكى انحراف استاندارد

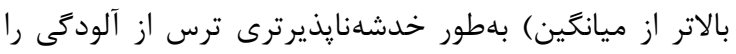

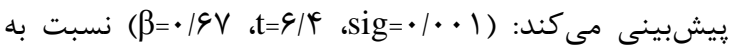
سطوح پايين مستعدبودن براى ابتلا به بيمارى مسرى (نمرات

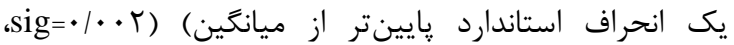

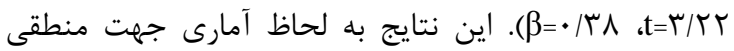

شده است. קنانكه اطلاعات جدول ا نشان مىدهند، تمامى

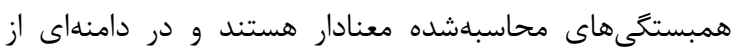

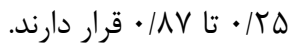

نقش تعديلكننده آسيب بذيرى ادراكشده نسبت به

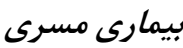

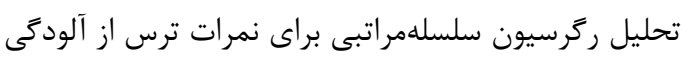

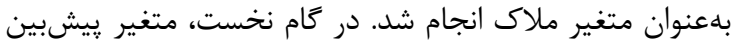

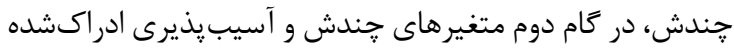
نسبت به بيمارى مسرى و در كام سوم متغيرهاى حندشى

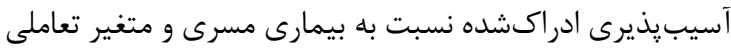
جندش X آسيب يذيرى ادراكشده نسبت به بيمارى مسرى وارد

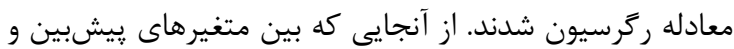

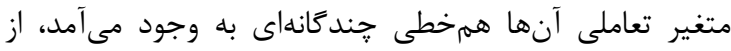

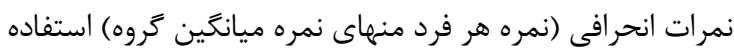

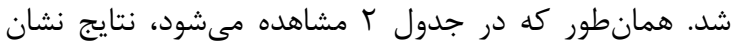

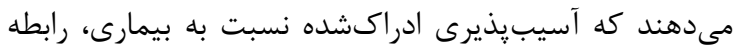

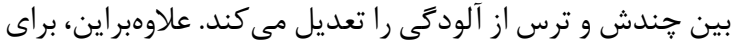

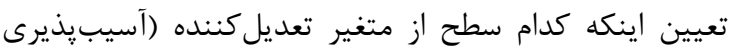

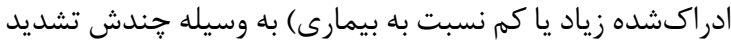

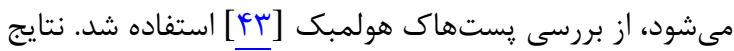

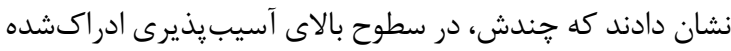

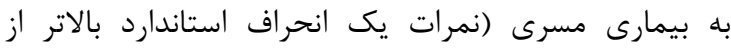

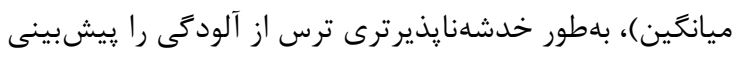

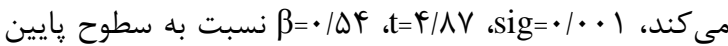

جدول ץ: نتايج تحليل ركرسيون متغير تعديل كننده آسيبذيذيرى ادراكشده نسبت به بيمارى مسرى

\begin{tabular}{|c|c|c|c|c|}
\hline $\mathbf{R}^{2}$ & $\mathbf{t}$ & $\boldsymbol{\beta}$ & متغيرهاى مورد بررسى & ترتيب \\
\hline$\cdot / \pi \Delta$ & $*|r / V|$ & $\cdot 109$ & جندش & Fام يك \\
\hline$\cdot 10$ & 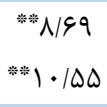 & $\cdot / r V$ & آسيب بِيرى ادراكشده نسبت به بيمارى مسرى & كَام دو \\
\hline . $/ \Delta T$ & 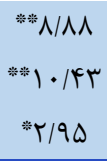 & $\begin{array}{l}\cdot / T Y \\
\cdot / 4 F \\
. / 11\end{array}$ & 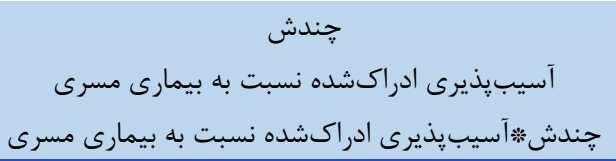 & كام سه \\
\hline
\end{tabular}

* معنادارى در سطح ب ...

جدول با: تحليل ركرسيون متغير تعديل كننده مستعدبودن براى ابتلا به بيمارى مسرى به لحاظ ذهنى

\begin{tabular}{|c|c|c|c|c|}
\hline $\mathbf{R}^{2}$ & $\mathbf{t}$ & $\boldsymbol{\beta}$ & متغير هاى مورد بر رسى & ترتيب \\
\hline$\cdot / \pi \Delta$ & 粺|r/VI & $\cdot 109$ & جندش & 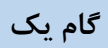 \\
\hline \multirow{2}{*}{$\cdot|4|$} & 稿IY/MY & $\cdot / \Delta T$ & جندش & \multirow{2}{*}{ 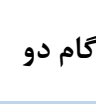 } \\
\hline & $* 0 / 9 \Lambda$ & $\cdot / r \Delta$ & مستعدبودن براى ابتلا به بيمارى مسرى به لحاظ ذهنى & \\
\hline \multirow{3}{*}{. $/ 4 t$} & 楼I $\mid Y / T$. & $\cdot \mid \Delta T$ & 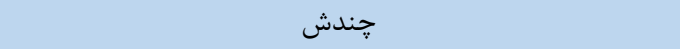 & \multirow{3}{*}{ 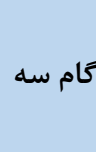 } \\
\hline & $*$ * & $\cdot / 4 \varphi$ & مستعدبودن براى ابتلا به بيمارى مسرى به لحاظ ذهنى & \\
\hline & $* T / T$. & $\cdot 1 \cdot 90$ & جندش*مستعدبودن براى ابتلا به بيمارى مسرى به لحاظ ذهنى & \\
\hline
\end{tabular}

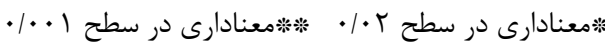


بدينمعنا كه فعالسازى ايمنى رفتارى مىتواند به جلوكيرى از

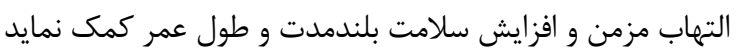

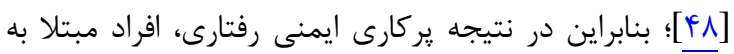

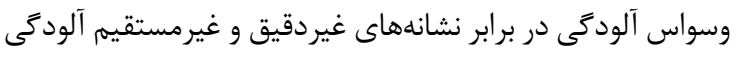

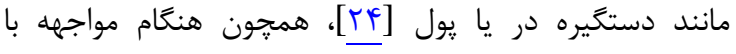

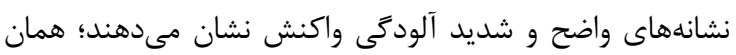

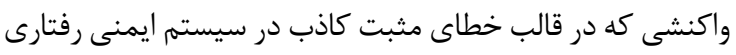
مطرح شده است [عب].

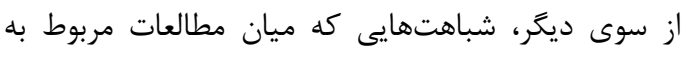

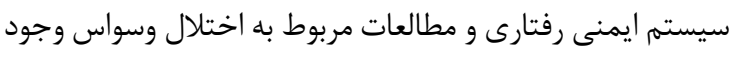

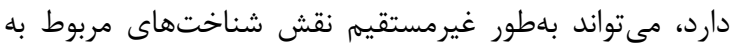

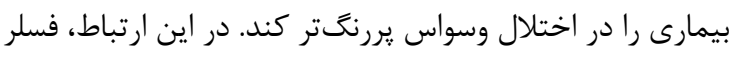

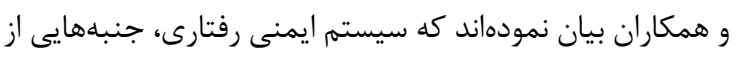

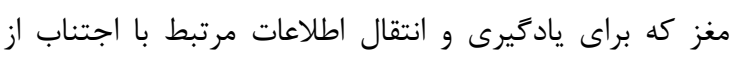

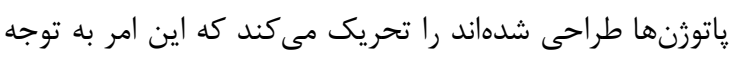

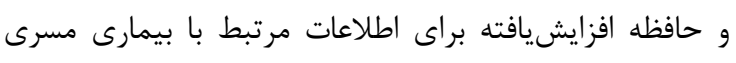

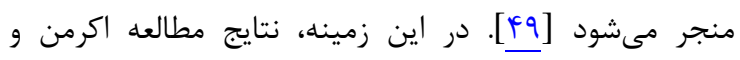

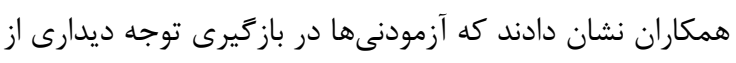

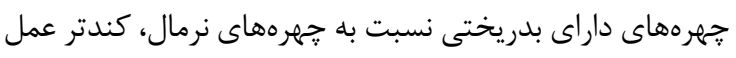

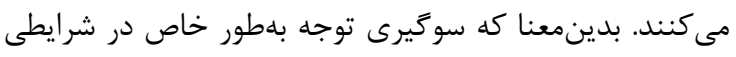

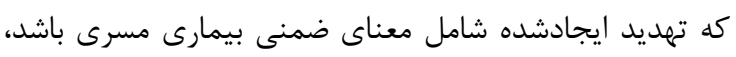

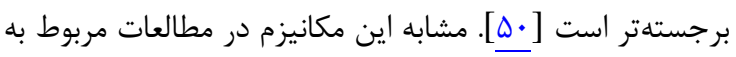

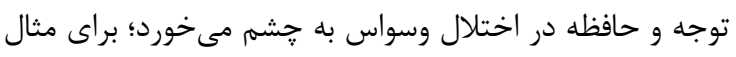

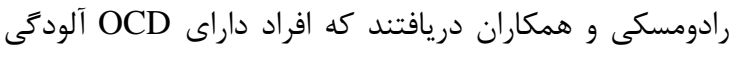

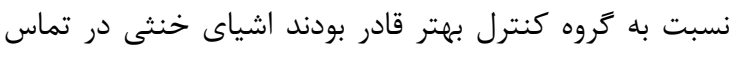

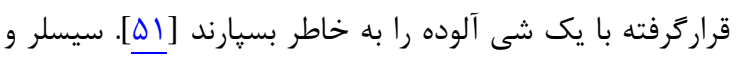

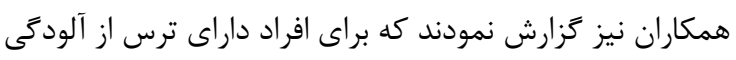

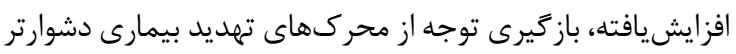
مىباشد [Qr] بلهطور كلى، نتايج مطالعه حاضر با مطالعاتى كه كاركرد

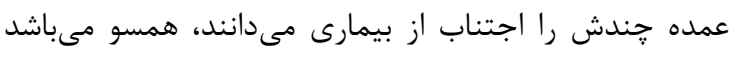

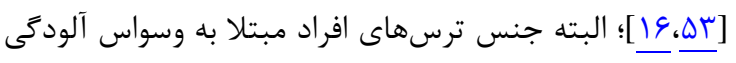

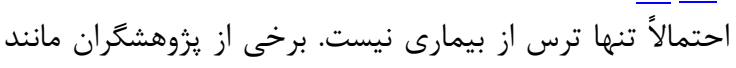

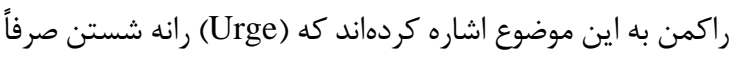

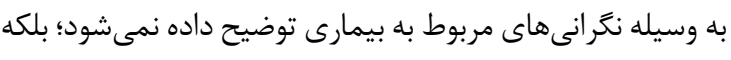

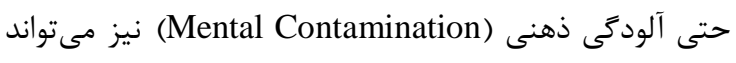

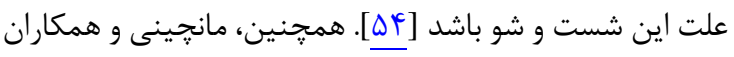

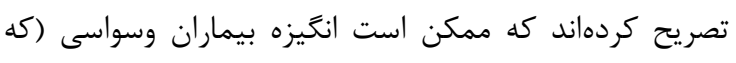

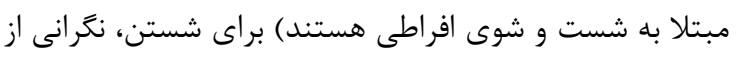

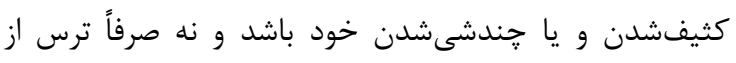

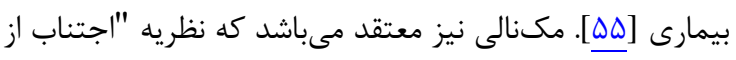

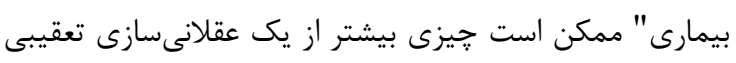

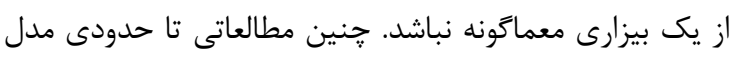

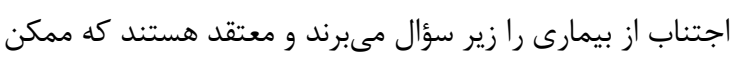

تعامل را تأييد مى كنند: سطح بالاى مستعدبودن براى ابتلا به

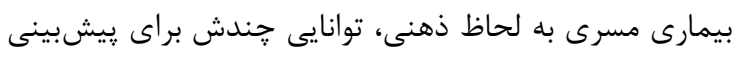
ترس از آلودگى را تشديد مي كند.

بحث

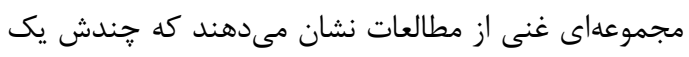

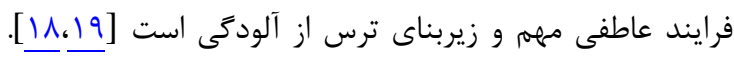

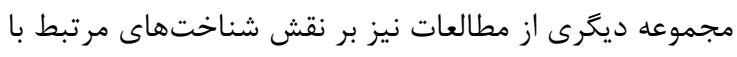

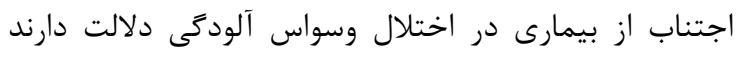

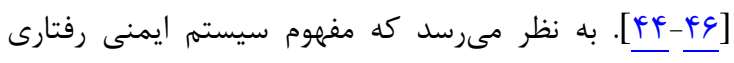

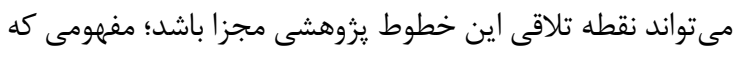

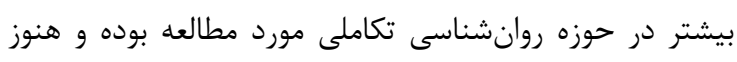

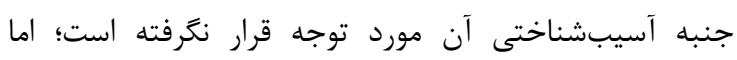

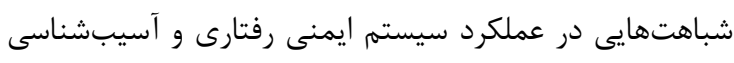

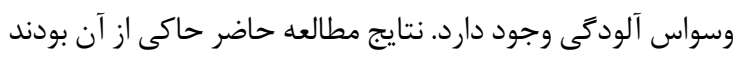

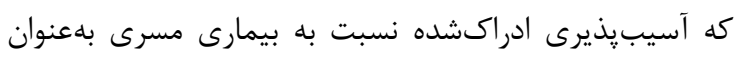

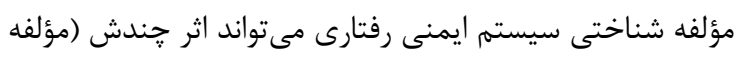

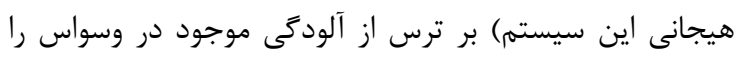

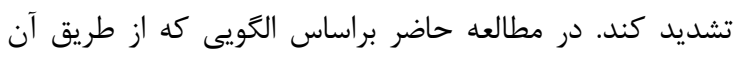

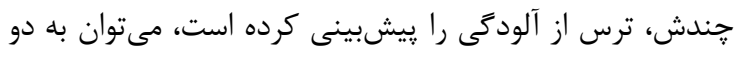

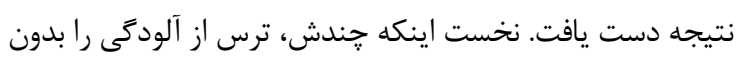

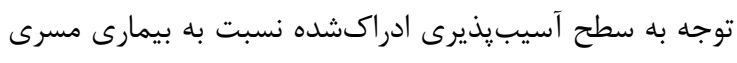

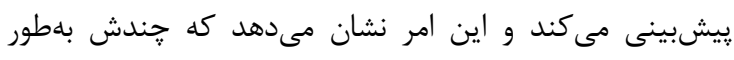

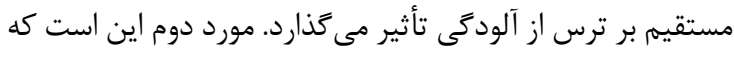

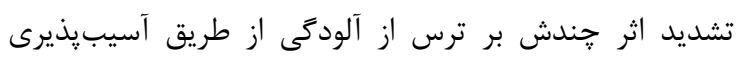

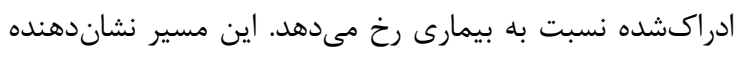

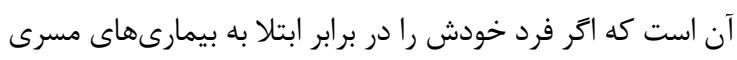

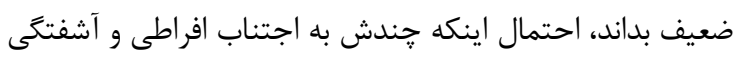

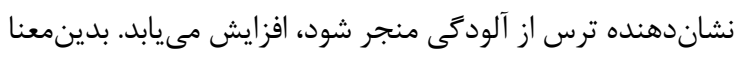

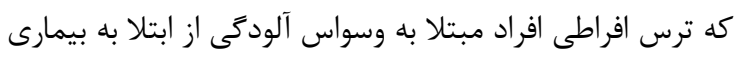

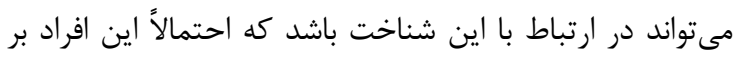

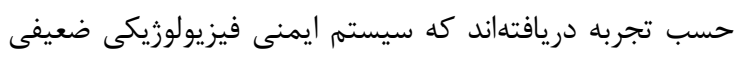

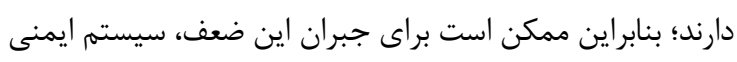

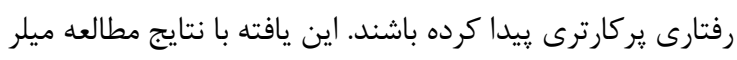

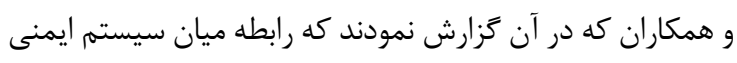

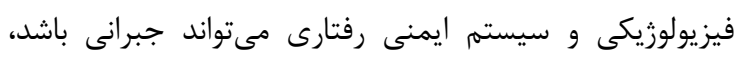

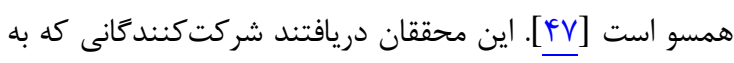

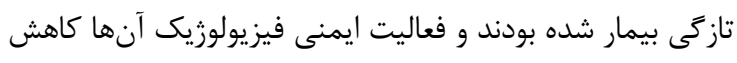

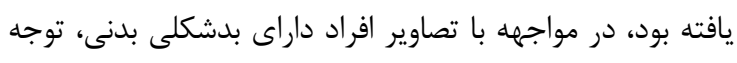

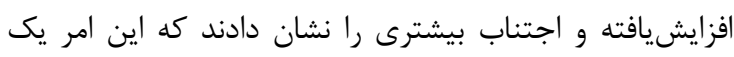

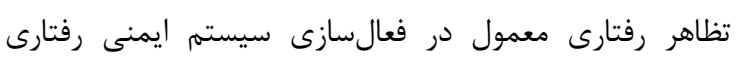

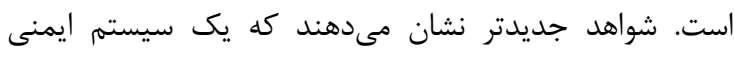

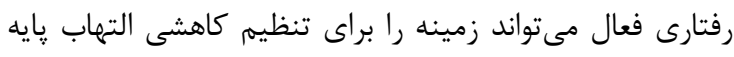
(Down Regulation of Basal Inflammation) 
محرى است سبب مىشود كه آزمودنىها سود بيشترى از

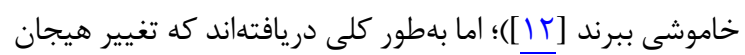

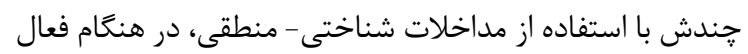

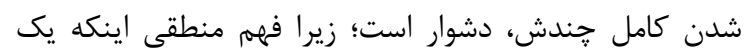

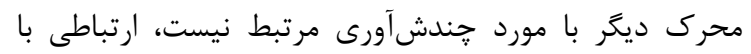

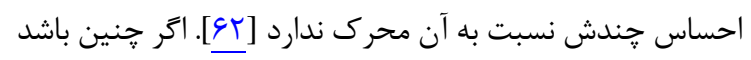

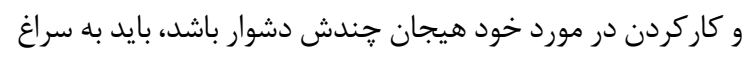

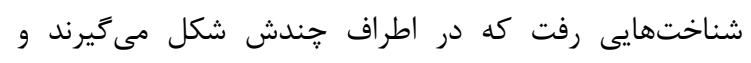

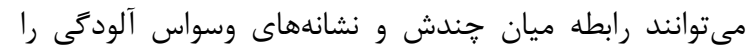
تعديل يا ميانجى گرى كنند. بر اين اساس مطابق بان بان نتايج مطالعه

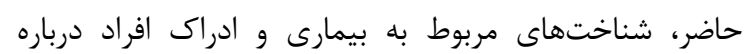

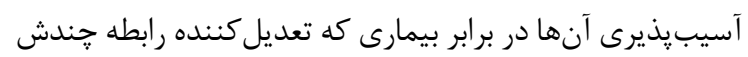

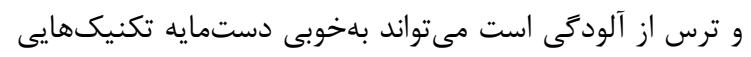

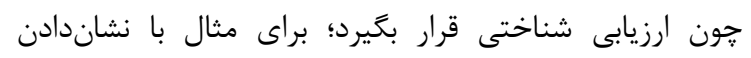

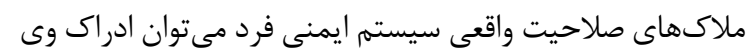

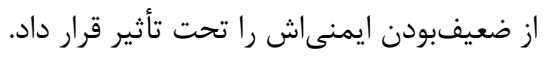

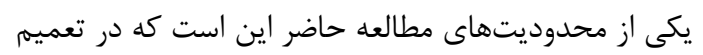

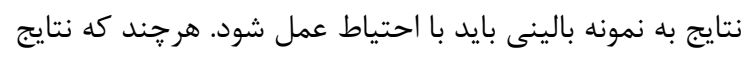

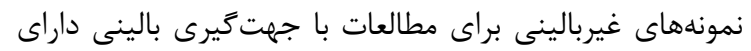

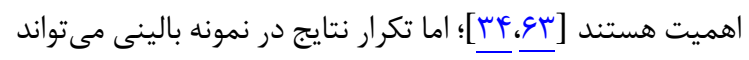

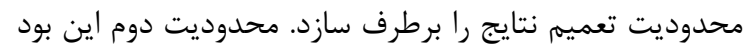

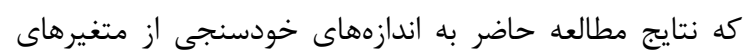

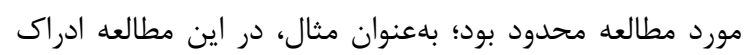

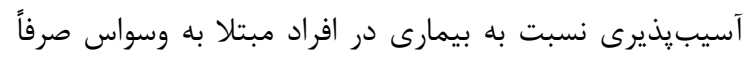

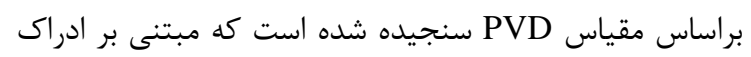

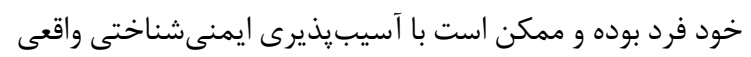

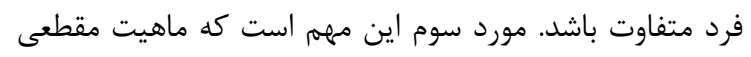

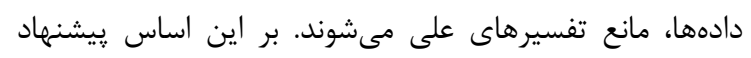

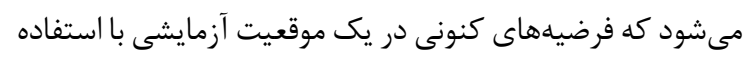

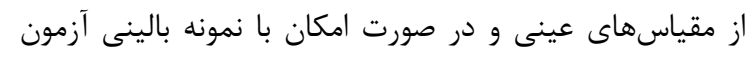

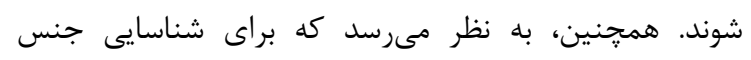

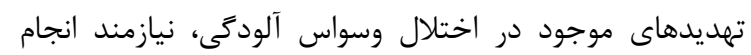

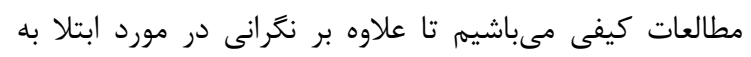

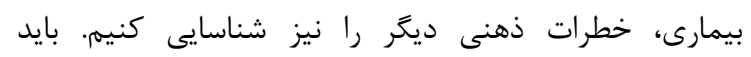

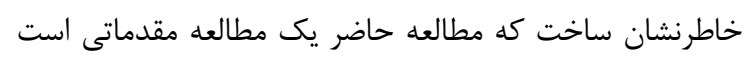

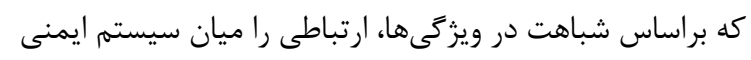

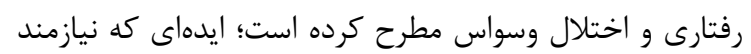
بررسىهاى بيشتر مى باشد. در اين راستا، سيسلر و و همكاران

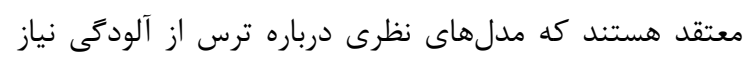

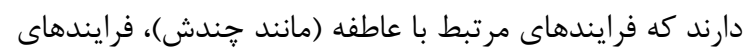

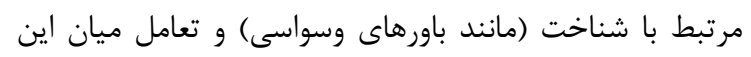

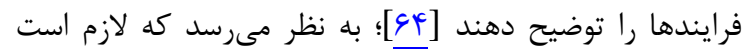

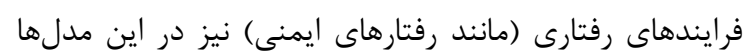

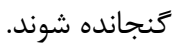

است اجتناب از بيمارى، مهمترين انكَيزه در جندش و در آيينهاى

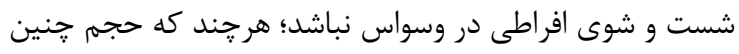

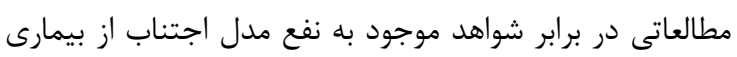

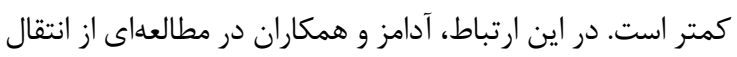
اطلاعات بهعنوان يك فرايند شناختى آمادهسازى (Primming)

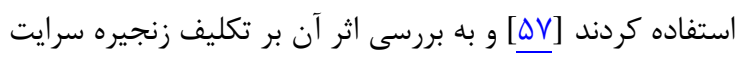

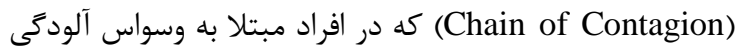

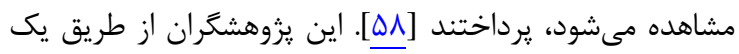

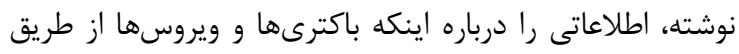

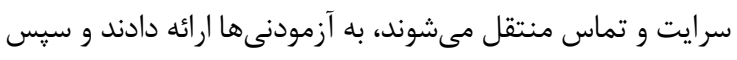

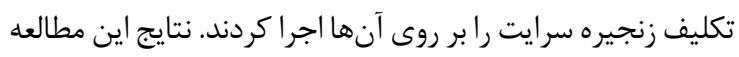

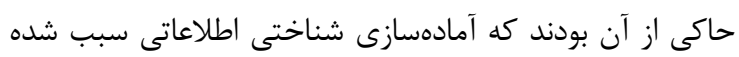

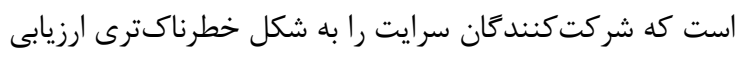

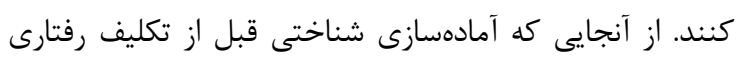

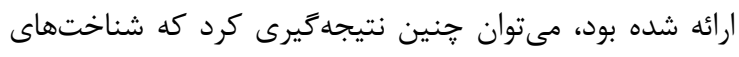

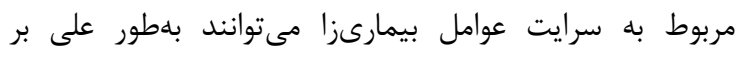

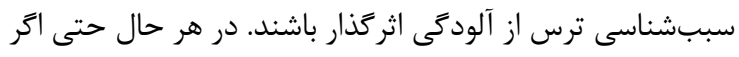

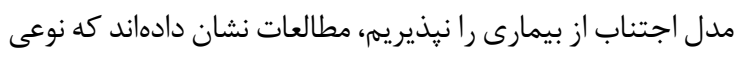

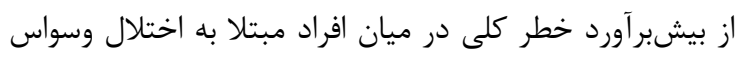

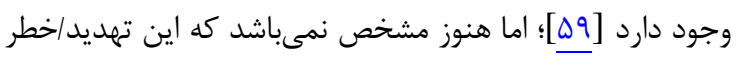

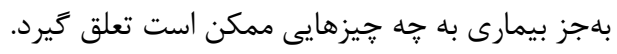

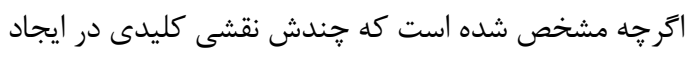

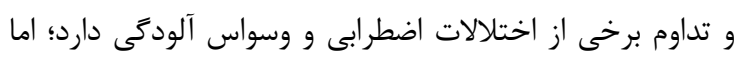

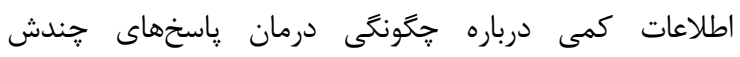

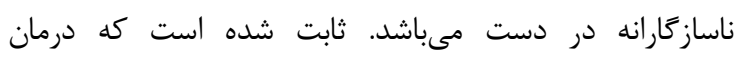

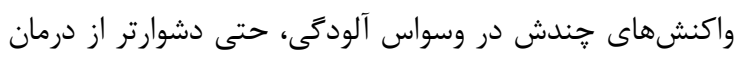

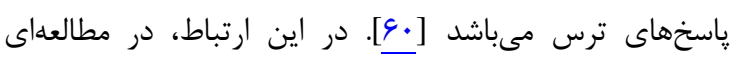

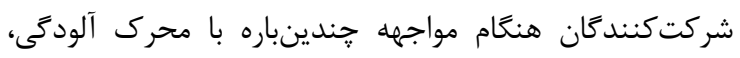

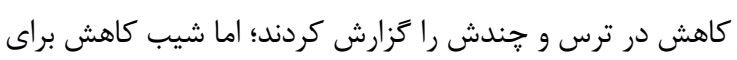

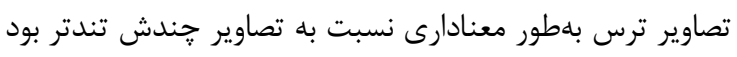

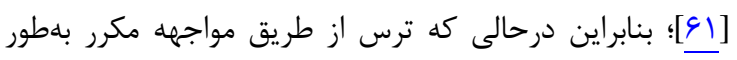

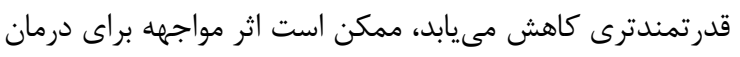

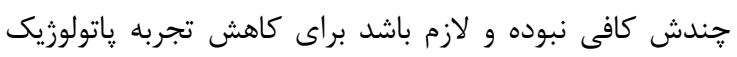

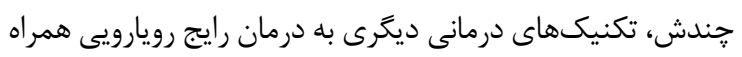
با جلوكيرى از ياسخ (Exposure and Response Prevention)

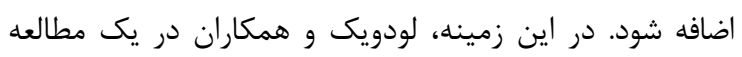

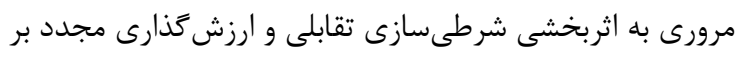

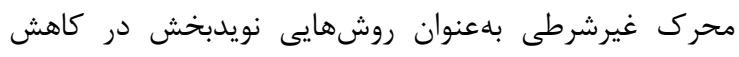

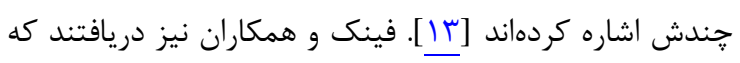

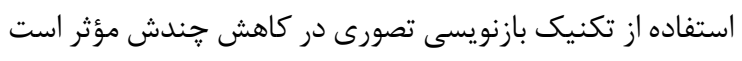

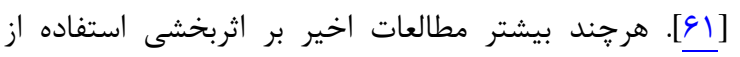
تكنيك ارزيابى شناختى (Cognitive Reappraisal) متمركز

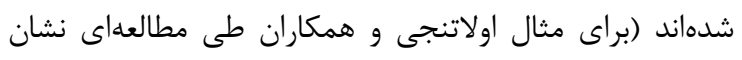

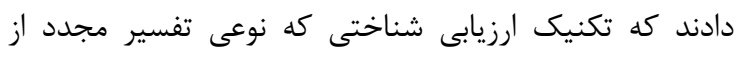




$$
\begin{aligned}
& \text { تشكر و قدردانى } \\
& \text { اين مقاله بركرفته از پاياننامه دوره دكترى روانشناسى }
\end{aligned}
$$

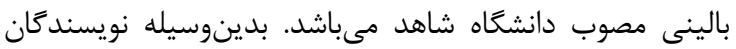

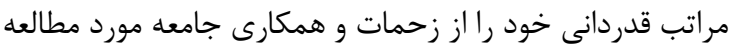

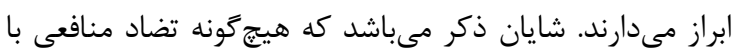

$$
\begin{aligned}
& \text { نتايج مطالعه كزارش نشده است. }
\end{aligned}
$$

\section{REFERENCES}

1. Brady RE, Adams TG, Lohr JM. Disgust in contaminationbased obsessive-compulsive disorder: a review and model. Expert Rev Neurother. 2010;10(8):1295-305. PMID: 20662755 DOI: $10.1586 /$ ern.10.46

2. Hollander E, Kwon JH, Stein DJ, Broatch J, Rowland CT, Himelein CA. Obsessive-compulsive and spectrum disorders: overview and quality of life issues. J Clin Psychiatry. 1996;57(Suppl 8):3-6. PMID: 8698678

3. Kessler RC, Berglund P, Demler O, Jin R, Merikangas KR, Walters EE. Lifetime prevalence and age-of-onset distributions of DSM-IV disorders in the National Comorbidity Survey Replication. Arch Gen Psychiatry. 2005;62(6):593-602. PMID: 15939837 DOI: 10.1001/ archpsyc.62.6.593

4. American Psychiatric Association. Diagnostic and statistical manual of mental disorders (DSM-5®). New York: American Psychiatric Pub; 2013.

5. Gilbert AR, Mataix-Cols D, Almeida JR, Lawrence N, Nutche J, Diwadkar V, et al. Brain structure and symptom dimension relationships in obsessive-compulsive disorder: a voxel-based morphometry study. J Affect Disord. 2008;109(1-2):117-26. PMID: 18342953 DOI: $10.1016 / j . j a d .2007 .12 .223$

6. Mataix-Cols D, van den Heuvel OA. Common and distinct neural correlates of obsessive-compulsive and related disorders. Psychiatr Clin North Am. 2006;29(2):391-410. PMID: 16650715 DOI: $10.1016 /$ j.psc.2006.02.006

7. van den Heuvel OA, Remijnse PL, Mataix-Cols D, Vrenken $\mathrm{H}$, Groenewegen HJ, Uylings HB, et al. The major symptom dimensions of obsessive-compulsive disorder are mediated by partially distinct neural systems. Brain. 2009;132(Pt 4):853-68. PMID: 18952675 DOI: 10.1093/brain/awn267

8. Rasmussen SA, Eisen JL. The epidemiology and clinical features of obsessive compulsive disorder. Psychiatr Clin North Am. 1992;15(4):743-58. PMID: 1461792

9. Rachman S, Hodgson RJ. Obsessions and compulsions. Englewood Cliffs, NJ: Prentice Hall; 1980.

10. Rachman S. Fear of Contamination: assessment \& treatment. Oxford: Oxford University Press; 2006.

11. Rachman S. Fear of contamination. Behav Res Ther. 2004;42(11):1227-55.

12. Olatunji BO, Berg H, Cox RC, Billingsley A. The effects of cognitive reappraisal on conditioned disgust in contamination-based OCD: An analogue study. J Anxiety Disord. 2017;51:86-93. PMID: 28705679 DOI: 10.1016/j. janxdis.2017.06.005

13. Ludvik D, Boschen MJ, Neumann DL. Effective behavioural strategies for reducing disgust in contamination-related OCD: a review. Clin Psychol Rev. 2015;42:116-29. PMID: 26190372 DOI: 10.1016/j.cpr.2015.07.001

14. Rozin P, Haidt J, McCauley CR. Disgust. In: Lewis M, Havilan-Jones JM, editors. Handbook of emotions. $2^{\text {nd }}$ ed. New York: Guilford Press; 2000. P. 637-53.

15. Rozin P, Fallon AE. A perspective on disgust. Psychol Rev. 1987;94(1):23-41. PMID: 3823304

16. Oaten M, Stevenson RJ, Case TI. Disgust as a diseaseavoidance mechanism. Psychol Bull. 2009;135(2):303-21. PMID: 19254082 DOI: $10.1037 / \mathrm{a} 0014823$

17. Cisler JM, Adams TG, Brady RE, Bridges AJ, Lohr JM, Olatunji BO. Unique affective and cognitive processes in contamination appraisals: implications for contamination fear. J Anxiety Disord. 2011;25(1):28-35. PMID: 20691567
نتبحهن تيوى

يافتههاى بلدستآمده از مطالعه حاضر به شناخت

مكانيزمهاى اثر جندش بر ترس از آلودگى بهويزه نقش شناختها در تعامل با هيجان و ييشبرد نظريه رو به رشد جندش و درمان

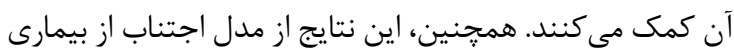
مطرحشده براى جندش و بيشفعالى احتمالى سيستم ايمنى رفتارى در اختلال وسواس آلودگى حمايت مىنمايند.

DOI: $10.1016 /$ j.janxdis.2010.07.002

18. Olatunji BO, Sawchuk CN, Lohr JM, de Jong PJ. Disgust domains in the prediction of contamination fear. Behav Res Ther. 2004;42(1):93-104. PMID: 14744526

19. Moretz MW, McKay D. Disgust sensitivity as a predictor of obsessive-compulsive contamination symptoms and associated cognitions. J Anxiety Disord. 2008;22(4):707-15. PMID: 17719199 DOI: 10.1016/j.janxdis.2007.07.004

20. Lawrence NS, An SK, Mataix-Cols D, Ruths F, Speckens A, Phillips ML. Neural responses to facial expressions of disgust but not fear are modulated by washing symptoms in OCD. Biol Psychiatry. 2007;61(9):1072-80. PMID: 17097073 DOI: 10.1016/j.biopsych.2006.06.033

21. Phillips ML, Marks IM, Senior C, Lythgoe D, O'Dwyer AM, Meehan O, et al. A differential neural response in obsessivecompulsive disorder patients with washing compared with checking symptoms to disgust. Psychol Med. 2000; 30(5):1037-50. PMID: 12027041

22. Taboas W, Ojserkis R, McKay D. Change in disgust reactions following cognitive-behavioral therapy for childhood anxiety disorders. Int J Clin Health Psychol. 2015;15(1):1-7. PMID: 30487816 DOI: $10.1016 /$ j.ijchp.2014.06.002

23. Athey AJ, Elias JA, Crosby JM, Jenike MA, Pope HG Jr, Hudson JI, et al. Reduced disgust propensity is associated with improvement in contamination/washing symptoms in obsessive-compulsive disorder. J Obsessive Compuls Relat Disord. 2015;1(4):20-4. PMID: 25485229 DOI: 10.1016/j.jocrd.2014.11.001

24. Adams TG, Cisler JM, Brady RE, Lohr JM, Olatunji BO. Preliminary psychometric evidence for distinct affective and cognitive mechanisms mediating contamination aversion. $J$ Psychopathol Behav Assess. 2013;35(3):375-88. DOI: 10.1007/s10862-013-9343-8

25. Kurzban R, Leary MR. Evolutionary origins of stigmatization: the functions of social exclusion. Psychol Bull. 2001;127(2):187-208. PMID: 11316010

26. Schaller M, Park JH. The behavioral immune system (and why it matters). Curr Dir Psychol Sci. 2011;20(2):99-103. DOI: $10.1177 / 0963721411402596$

27. Rubio-Godoy M, Aunger R, Curtis V. Serotonin--a link between disgust and immunity? Med Hypotheses. 2007; 68(1):61-6. PMID: 16928421 DOI: 10.1016/j.mehy.2006.06.036

28. Fessler DM, Eng SJ, Navarrete CD. Elevated disgust sensitivity in the first trimester of pregnancy: Evidence supporting the compensatory prophylaxis hypothesis. Evol Hum Behav. 2005;26(4):344-51. DOI: 0.1016/j.evolhumbehav.2004.12.001

29. Park JH, Schaller M, Crandall CS. Pathogen-avoidance mechanisms and the stigmatization of obese people. Evol Hum Behav. 2007;28(6):410-4. DOI: 10.1016/j.evolhumbehav. 2007.05.008

30. Park JH, Faulkner J, Schaller M. Evolved disease-avoidance processes and contemporary anti-social behavior: prejudicial attitudes and avoidance of people with physical disabilities. J Nonverbal Behav. 2003;27(2):65-87. DOI: 0.1023/A: 1023910408854

31. Schaller M, Duncan LA. The behavioral immune system: Its evolution and social psychological implications. Evolution and the social mind: Evolutionary psychology and social cognition. Sydney symposium of social psychology. New York: Routledge/Taylor \& Francis Group; 2007. P. 293-307.

32. Navarrete CD, Fessler DM. Disease avoidance and 
ethnocentrism: the effects of disease vulnerability and disgust sensitivity on intergroup attitudes. Evol Hum Behav. 2006;27(4):270-82. DOI: 10.1016/j.evolhumbehav.2005.12.001

33. Faulkner J, Schaller M, Park JH, Duncan LA. Evolved diseaseavoidance mechanisms and contemporary xenophobic attitudes. Group Proc Intergroup Relat. 2004;7(4):333-53. DOI: $10.1177 / 1368430204046142$

34. Burns GL, Formea GM, Keortge S, Sternberger LG. The utilization of nonpatient samples in the study of obsessive compulsive disorder. Behav Res Ther. 1995;33(2):133-44. PMID: 7887872

35. Thordarson DS, Radomsky AS, Rachman S, Shafran R, Sawchuk CN, Ralph Hakstian A. The vancouver obsessional compulsive inventory (VOCI). Behav Res Ther. 2004; 42(11):1289-314. PMID: 15381439 DOI: 10.1016/j.brat. 2003.08.007

36. Hodgson RJ, Rachman S. Obsessional-compulsive complaints. Behav Res Ther. 1977;15(5):389-95. PMID: 612339

37. Ghassemzadeh H, Shams G, Meysami A, Karamghadiri N. Psychometric properties of the persian version of the vancouver obsessional-compulsive inventory inventory (VOCI) in Iranian non-clinical sample. Psychology. 2017;8:206-25. DOI: 10.4236/psych.2017.81012

38. Duncan LA, Schaller M, Park JH. Perceived vulnerability to disease: development and validation of a 15-item self-report instrument. Pers Individ Dif. 2009;47(6):541-6. DOI: 10.1016/j.paid.2009.05.001

39. Olatunji BO, Williams NL, Tolin DF, Abramowitz JS, Sawchuk CN, Lohr JM, et al. The Disgust Scale: item analysis, factor structure, and suggestions for refinement. Psychol Assess. 2007;19(3):281-97. PMID: 17845120 DOI: 10.1037/1040-3590.19.3.281

40. Haidt J, McCauley C, Rozin P. Individual differences in sensitivity to disgust: a scale sampling seven domains of disgust elicitors. Pers Individ Dif. 1994;16(5):701-13. DOI: 10.1016/0191-8869(94)90212-7

41. Shams G, Foroughi E, Moretz MW, Olatunji BO. Factor Structure and psychometric properties of the persian disgust scale-revised: examination of specificity to symptoms of obsessive-compulsive disorder. Psychology. 2013;4(6):526. DOI: $10.4236 /$ psych.2013.46075

42. Tabachnick BG, Fidell LS, Ullman JB. Using multivariate statistics. Boston, MA: Pearson; 2001. P. 980.

43. Holmbeck GN. Post-hoc probing of significant moderational and mediational effects in studies of pediatric populations. $J$ Pediatr Psychol. 2002;27(1):87-96. PMID: 11726683 DOI: 10.1093/jpepsy/27.1.87

44. Mitte K. Trait-disgust vs. fear of contamination and the judgmental bias of contamination concerns. J Behav Ther Exp Psychiatry. 2008;39(4):577-86. PMID: 18359478 DOI: 10.1016/j.jbtep.2008.01.005

45. Verwoerd J, de Jong PJ, Wessel I, van Hout WJ. "If I feel disgusted, I must be getting ill": Emotional reasoning in the context of contamination fear. Behav Res Ther. 2013;51(3):1227. PMID: 23337180 DOI: 10.1016/j.brat.2012.11.005

46. Jones MK, Menzies RG. The cognitive mediation of obsessive-compulsive handwashing. Behav Res Ther. 1997;35(9):843-50. PMID: 9299804

47. Miller SL, Maner JK. Sick body, vigilant mind: the biological immune system activates the behavioral immune system. Psychol Sci. 2011;22(12):1467-71. PMID: 22058109 DOI: 10.1177/0956797611420166

48. Ackerman JM, Hill SE, Murray DR. The behavioral immune system: current concerns and future directions. Soc Personal Psychol Compass. 2018;12(2):e12371. DOI: 10.1111/spc3.12371

49. Fessler DM, Clark JA, Clint EK. Evolutionary psychology and evolutionary anthropology. The Handbook of Evolutionary Psychology. New Jersey: John Wiley \& Sons; 2015. P. 1-18

50. Ackerman JM, Becker DV, Mortensen CR, Sasaki T, Neuberg SL, Kenrick DT. A pox on the mind: Disjunction of attention and memory in the processing of physical disfigurement. J Exp Soc Psychol. 2009;45(3):478-85. PMID: 19578547 DOI: 10.1016/j.jesp.2008.12.008

51. Radomsky AS, Rachman S. Memory bias in obsessivecompulsive disorder (OCD). Behav Res Ther. 1999; 37(7):605-18. PMID: 10402686

52. Cisler JM, Olatunji BO. Components of attentional biases in contamination fear: evidence for difficulty in disengagement. Behav Res Ther. 2010;48(1):74-8. PMID: 19781691 DOI: 10.1016/j.brat.2009.09.003

53. Curtis V, Aunger R, Rabie T. Evidence that disgust evolved to protect from risk of disease. Proc Biol Sci. 2004;271(Suppl 4):S131-3. PMID: 15252963 DOI: $10.1098 / \mathrm{rsbl} .2003 .0144$

54. Rachman S. Pollution of the mind. Behav Res Ther. 1994;32(3):311-4. PMID: 8192629

55. Mancini F, Gragnani A, D'Olimpio F. The connection between disgust and obsessions and compulsions in a nonclinical sample. Pers Individ Dif. 2001;31(7):1173-80. DOI: 10.1016/S0191-8869(00)00215-4

56. McNally R. Disgust has arrived. $J$ Anxiety Disord. 2002;16(5):561-6. PMID: 12396212

57. Adams Jr TG, Cisler JM, Brady RE, Lohr JM. The effects of cognitive and affective priming on law of contagion appraisals. J Exp Psychopathol. 2012;3(3):470-8. DOI: 10.5127/jep.025911

58. Tolin DF, Worhunsky P, Maltby N. Sympathetic magic in contamination-related OCD. J Behav Ther Exp Psychiatry. 2004;35(2):193-205. PMID: 15210379 DOI: $10.1016 / j . j b t e p$. 2004.04.009

59. Tolin DF, Brady RE, Hannan S. Obsessional beliefs and symptoms of obsessive--compulsive disorder in a clinical sample. J Psychopathol Behav Assess. 2008;30(1):31-42. DOI: $10.1007 / \mathrm{s} 10862-007-9076-7$

60. Adams TG Jr, Willems JL, Bridges AJ. Contamination aversion and repeated exposure to disgusting stimuli. Anxiety Stress Coping. 2011;24(2):157-65. PMID: 20737324 DOI: $10.1080 / 10615806.2010 .506953$

61. Fink J, Pflugradt E, Stierle C, Exner C. Changing disgust through imagery rescripting and cognitive reappraisal in contamination-based obsessive-compulsive disorder. $J$ Anxiety Disord. 2018;54:36-48. PMID: 29421371 DOI: 10.1016/j.janxdis.2018.01.002

62. Mason EC, Richardson R. Looking beyond fear: the extinction of other emotions implicated in anxiety disorders. J Anxiety Disord. 2010;24(1):63-70. PMID: 19747796 DOI: 10.1016/j.janxdis.2009.08.007

63. Mitte K. Trait-disgust vs. fear of contamination and the judgmental bias of contamination concerns. J Behav Ther Exp Psychiatry. 2008;39(4):577-86. PMID: 18359478 DOI: 10.1016/j.jbtep.2008.01.005

64. Cisler JM, Brady RE, Olatunji BO, Lohr JM. Disgust and obsessive beliefs in contamination-related OCD. Cognit Ther Res. 2010;34(5):439-48. PMID: 20877585 DOI: $10.1007 / \mathrm{s} 10608-009-9253-\mathrm{y}$ 